\title{
Inclusion of water and KDP as a mechanism for controlling structural and dielectric parameters in PVDF films
}

\author{
C A O ROCHA ${ }^{1,2}$, L G PATERNO ${ }^{3}$ and A M CESCHIN ${ }^{1, *}$ \\ ${ }^{1}$ Departamento de Engenharia Elétrica, Universidade de Brasília, Campus Darcy Ribeiro, 70.019-970 Brasília, Brazil \\ ${ }^{2}$ Instituto Federal de Educação, Ciência e Tecnologia do Norte de Minas Gerais, 38.680-000 Montes Claros, Brazil \\ ${ }^{3}$ Instituto de Química, Universidade de Brasília, 70.019-970 Brasília, Brazil \\ *Author for correspondence (artemis@ pgea.unb.br)
}

MS received 14 January 2019; accepted 24 March 2019

\begin{abstract}
In this work, the possibility of improving the microstructural and dielectric properties of poly(vinylidene fluoride) (PVDF) by the addition of potassium dihydrogen phosphate (KDP) to the polymer matrix is speculated. Both PVDF and KDP are ferroelectric and piezoelectric materials, so the combination may result in a synergistic interaction. PVDF and KDP were dissolved in water/dimethylformamide at $70^{\circ} \mathrm{C}$. The solutions were deposited by casting to obtain films. The samples were characterized by energy-dispersive X-ray spectroscopy, scanning electron microscopy, X-ray diffraction (XRD) and Fourier transform infrared (FTIR) spectroscopy. XRD tests of the samples showed that hydrated PVDF films resume crystallinity up to a maximum content of $3.0 \%$ by weight of KDP. FTIR confirmed the possibility of adjusting the intensity of the alpha $(\alpha)$ and beta $(\beta)$-phase peaks in the polymer through water and KDP contents. Finally, the dielectric constant and the dielectric loss factor of the new materials at room temperature were determined.
\end{abstract}

Keywords. KDP; PVDF; ferroelectric; piezoelectric; sensor; actuator.

\section{Introduction}

Recently, blends and composite films have become interesting alternatives in research that aim to increase the performance of electroactive layers in electronic devices such as sensors, actuators and supercapacitors. Dielectric nanocomposites are materials generally composed of a polymer matrix and inorganic/organic fillers capable of enhancing the properties of both [1]. It is possible that a combination of two or more elements shows improved dielectric properties depending on the type and nature of the polymer matrices as well as their appropriate fillers [2].

Poly(vinylidene fluoride) (PVDF) is a semi-crystalline polymer of remarkable chemical resistance, known for its ferroelectric, pyroelectric and piezoelectric nature. It has high thermal stability, high chemical and mechanical resistance, as well as excellent ageing resistance in addition to good processability $[3,4]$. PVDF is formed by repeating units of $-\left(\mathrm{CH}_{2} \mathrm{CF}_{2}\right) n-[3]$. The spatial arrangement of $\mathrm{CH}_{2}$ and $\mathrm{CF}_{2}$ groups along the polymer chains contributes to their unique properties [4]. The Van der Waals radius of fluorine $(1.35 \AA)$ is slightly higher than that of hydrogen $(1.2 \AA)$ [5]. Therefore, different arrangements define different crystalline phases and the so-called phases $\alpha$ and $\beta$ are the most interesting. The $\alpha$-phase is the most stable and from it, all other ones can be obtained. The $\alpha$-phase is non-polar and has an armchair trans-gauche (TGTG') conformation. The $\beta$-phase is the most polar [6] and has a conformation of trans-trans zig-zag type (TTTT). The $\gamma$-phase is also polar and has a TTTGTTTG' conformation [6].

PVDF films have great potential for applications in microelectronics, such as transducers and non-volatile memory devices [7]. Because it has a low level of extractables, PVDF can be considered as a pure polymer; which makes it a suitable candidate in biomedical and bio-separation applications [4]. PVDF membranes have been widely applied in the treatment of general purpose water separation or purification [3]. Plastic materials have the advantages of being more flexible, lighter and economically more viable than ceramics. In addition, PVDF is mouldable in the most diverse forms, although its performance is still much lower than that of ceramics.

Therefore, modifying this material has been recurrent having the intention of adjusting or intensifying electrical parameters, such as its electrical conductivity, dielectric permittivity and piezoelectric constant. There are several reports of studies incorporating metallic or ceramic nano-fillings, such as lead zirconate titanate. Also recurrent, for example, is the mixing of PVDF to graphene oxide or a copolymer, to induce the formation of the polar $\beta$-phase. On the other hand, potassium dihydrogen phosphate $(\mathrm{KDP})\left(\mathrm{KH}_{2} \mathrm{PO}_{4}\right)$ is an inorganic salt in which the phosphate $\left(\mathrm{PO}_{4}^{3-}\right)$ groups are linked together by hydrogen bonds. The behaviour of the protons in these bonds apparently determines the ferroelectric nature of KDP crystals [8]. KDP crystals are also polymorphs. 
When heated to temperatures $>123 \mathrm{~K}$ (Curie point), the crystals undergo a transition from the ferroelectric phase to the para-electric phase $[8,9]$. KDP is a piezoelectric salt at room temperature [8].

In the present study, PVDF hybrid membranes filled with KDP crystals were prepared. The possibility of cooperative interaction between PVDF and KDP is a motivating element of this research. However, PVDF is soluble in organic solvents, such as dimethylformamide (DMF) or dimethylacetamide [10,11] while KDP is soluble in water [11]. Therefore, a mixture of water and DMF was prepared to dissolve KDP in PVDF. It was decided to use large amounts of water to ensure a good dissolution of KDP, which implies the production of highly hydrated films. The films were produced by casting the solutions in Petri dishes and subsequent oven drying.

\section{Experimental}

\subsection{Materials}

PVDF (molar mass of $10^{5} \mathrm{~g} \mathrm{~mol}^{-1}$ ) in the form of powder and KDP (molar mass of $136.09 \mathrm{~g} \mathrm{~mol}^{-1}$ ) in the form of crystals were obtained from Sigma Aldrich. $N, N$-dimethylformamide (density $0.944 \mathrm{~g} \mathrm{ml}^{-1}$ ) was purchased from Dinâmica.

\subsection{Procedure}

Initially, KDP was dissolved in $4 \mathrm{ml}$ of ultrapure water, subjected to magnetic stirring for $10 \mathrm{~min}$, while $6 \mathrm{ml}$ of DMF were dripped. This stirring was continued for another $20 \mathrm{~min}$, until a homogeneous solution was obtained and then $0.5 \mathrm{~g}$ of PVDF was added slowly under continued magnetic stirring. Three PVDF/KDP mixtures in water/DMF, named P0.5, P3 and $\mathrm{P} 4$, which differed from each other by their KDP content alone, were prepared as shown in table 1 . These mixtures were kept under magnetic stirring for $12 \mathrm{~h}$ at room temperature and then for another $4 \mathrm{~h}$ at a controlled temperature of $70^{\circ} \mathrm{C}$. Thereafter, $7 \mathrm{ml}$ of the mixture was collected with the aid of a graduated pipette, and poured into a glass Petri dish with a diameter equal to $50 \mathrm{~mm}$. For evaporation of the solvent and crystallization of the material, all samples were placed in an oven at $70^{\circ} \mathrm{C}$ for $18 \mathrm{~h}$. Two PVDF control films, free of KDP, were also prepared from the dissolution of $0.5 \mathrm{~g}$ of PVDF in $6 \mathrm{ml}$ of DMF, sample $\mathrm{C} 1$, and dissolution of $0.5 \mathrm{~g}$ of PVDF in the solution of $4 \mathrm{ml}$ of water/6 $\mathrm{ml} \mathrm{DMF}$, sample $\mathrm{C} 2$.

For dielectric characterization, gold was deposited on the surface of pieces of each sample of the composite. The deposition of gold for this purpose was performed through the Sputter Edwards Scancoat Six. The gold-plated samples were again cut into rectangles forming parallel plate capacitors with an area of $1.5 \times 1.5 \mathrm{~cm}$. Figure 1 shows the films $\mathrm{C} 1, \mathrm{C} 2, \mathrm{P} 0.5$, $\mathrm{P} 3$ and $\mathrm{P} 4$ after being removed from the oven, and the flexible capacitor made with the sample P3.
Table 1. Percentages of KDP in relation to the PVDF in samples $\mathrm{C} 1, \mathrm{C} 2, \mathrm{P} 0.5, \mathrm{P} 3$ and $\mathrm{P} 4$ are in the first row.

\begin{tabular}{lccccc}
\hline Samples & C1 & C2 & P0.5 & P3 & P4 \\
\hline KDP/PVDF (wt\%) & 0.0 & 0.0 & 0.5 & 3.0 & 4.0 \\
Water/DMF (v/v) & $0 / 3$ & $2 / 3$ & $2 / 3$ & $2 / 3$ & $2 / 3$ \\
\hline
\end{tabular}

The second row shows the reasons for the volumes of the solvents (water and DMF) present in the precursor samples of the films.
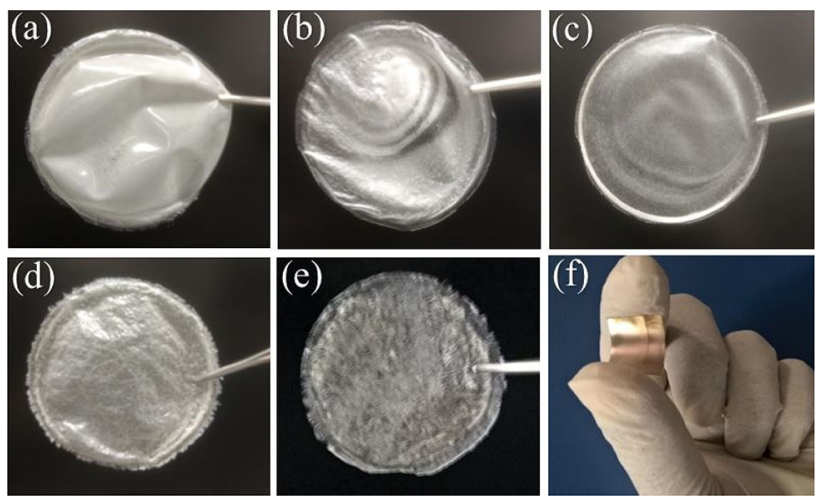

Figure 1. Physical appearance of samples of: (a) C1, (b) C2, (c) P0.5, (d) P3 and (e) P4. In (f), a sample of the capacitor made from the PVDF $+3 \mathrm{wt} \% \mathrm{KDP}$ sample is shown.

\section{Results}

\subsection{Thickness measurements}

The thicknesses of the PVDF/KDP hybrid films were measured using an Instrutherm Digital Thickness Gauge model ME-240. The values of the average thicknesses as shown in table 2 were obtained by taking 10 measurements of thickness at different points on the surface of the same sample. The transition from $\mathrm{C} 1$ to $\mathrm{C} 2$ results in swelling due to the effect produced by water. The hydrophilicity of KDP causes water absorption and consequent volume decrease. However, the increased density caused by contents of 3.0 and $4.0 \mathrm{wt} \%$ KDP cannot be ignored because they cause an increase in the average thickness of the films P3 and P4.

Table 2. Average thickness of the nanocomposite films of pure PVDF (C1) and PVDF hydrated with $0 \mathrm{wt} \%(\mathrm{C} 2), 0.5 \mathrm{wt} \%$ (P0.5), $3 \mathrm{wt} \%(\mathrm{P} 3)$ and $4 \mathrm{wt} \%(\mathrm{P} 4)$ of KDP.

\begin{tabular}{lccccc}
\hline Samples & C1 & C2 & P0.5 & P3 & P4 \\
\hline $\begin{array}{l}\text { Average film } \\
\text { thickness }(\mu \mathrm{m})\end{array}$ & 80.11 & 96.10 & 80.55 & 120.56 & 120.47 \\
\hline
\end{tabular}



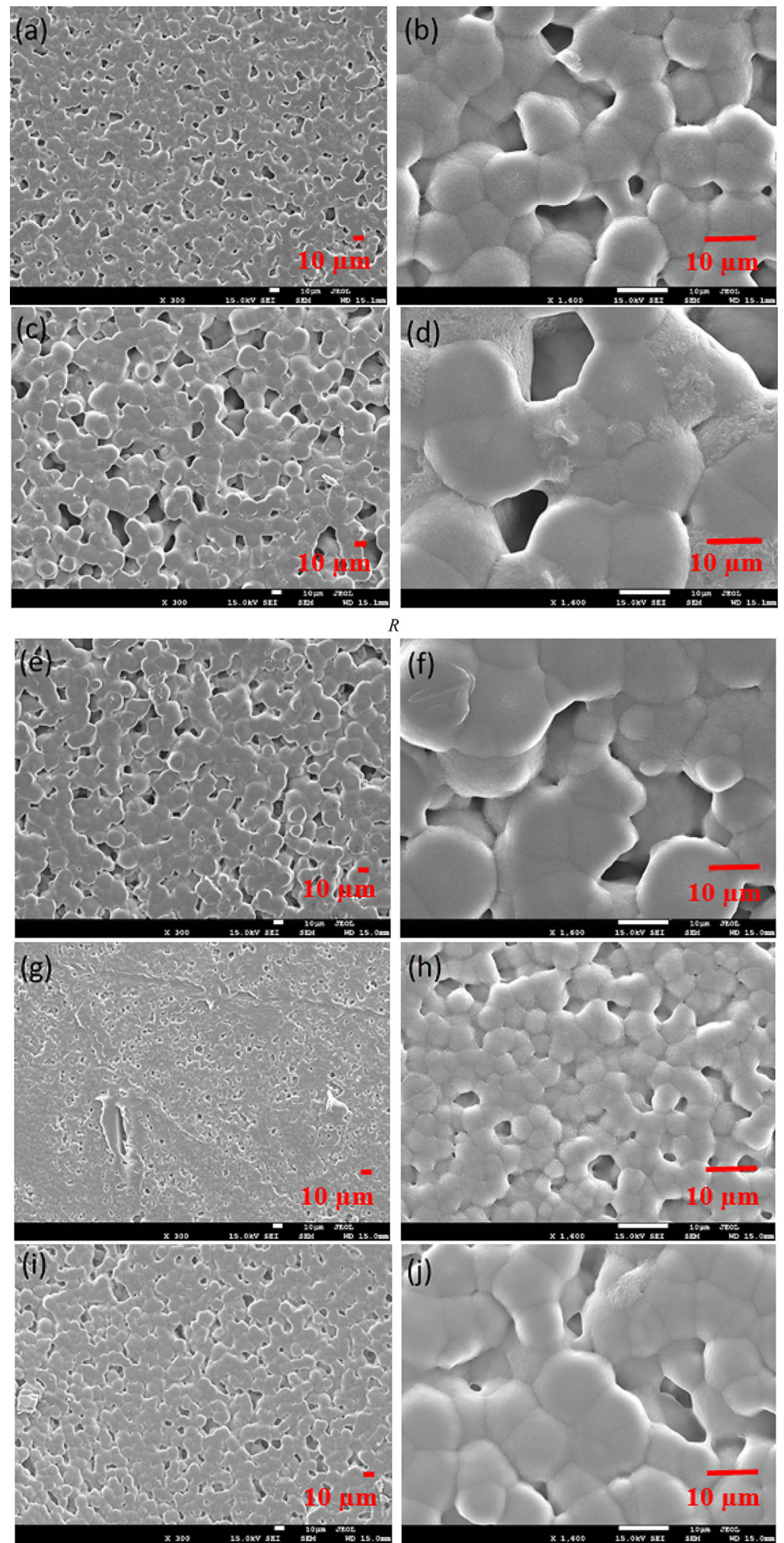

Figure 2. Sequentially, the SEM of the samples: (a) C1 magnified $300 \times$; (b) C1 magnified 1600×; (c) C2 magnified 300×; (d) C2 magnified 1600×; (e) P0.5 magnified 300×; (f) P0.5 magnified 1600×; (g) P3 magnified 300×; (h) P3 magnified $1600 \times$; (i) P4 magnified $300 \times$ and (j) P4 magnified $1600 \times$. 


\subsection{SEM and EDS}

Electron microscopy was preceded by the fixation of pieces $(0.5 \times 0.5 \mathrm{~cm})$ of each sample in brass holders, through carbon adhesive. The materials were then covered with gold $(10 \mathrm{~nm}$ thick) through a LEICA SCD 500 sputter coater under conditions of $40.0 \mathrm{mV}$ for $60 \mathrm{~s}$. The surface morphology of the samples was observed with a scanning electron microscopy (SEM) JEOL JSM-7000F SEM belonging to the University of Brasília, with a voltage of $15.0 \mathrm{kV}$. To prove the presence of KDP in the sample composition, energy scattering X-ray spectroscopy (EDS) spectra of the sample P3 were also recorded.

Figure 2 shows sequentially, top to bottom, electronic images of surfaces in samples C1, C2, P0.5, P3 and P4. Besides, these images are much appreciated but they differ in magnification from 300 to 1600 times. The presence of micropores in film $\mathrm{Cl}$ (figure $2 \mathrm{a}$ and $\mathrm{b}$ ) are observed. This porosity apparently distributes uniformly along the surface. Figure $2 \mathrm{c}$ and $\mathrm{d}$ shows a $\mathrm{C} 2$ film with a pore surface quantity numerically lower than the $\mathrm{C} 1 \mathrm{film}$, but these pores are clearly larger. The hydrophobicity of PVDF increases the possibility of water accumulation in certain regions, which is evidence of some incompatibility between PVDF and water. Therefore, a pore size increase may be a consequence of site vacancy due to the loss of solvent by the evaporation process. The KDP is quite hydrophilic and absorbs water from the system, both before and during the evaporation process. The phenomenon is strongly influenced by the hydrophobicity of PVDF $v s$. hydrophilicity of KDP. In contrast to the addition of water, the addition of KDP causes an increase in the number of pores per area and a decrease in its size. Figure $2 \mathrm{e}$ and $\mathrm{f}$ refers to sample P0.5, while figure $2 \mathrm{~g}$ and $\mathrm{h}$ refers to sample P3. From the sample P4 (4wt\% KDP) as shown in figure $2 \mathrm{i}$ and $\mathrm{j}$, the pores increase in size and decrease in quantity. In figure 3, the EDS spectrum of sample P3 reveals energy peaks belonging to the $\mathrm{K}, \mathrm{P}$ and $\mathrm{O}$ atoms, relative to $\mathrm{KDP}$ and, $\mathrm{C}$ and $\mathrm{F}$, relative to $\mathrm{PVDF}$. This information proves the presence of KDP crystals in the polymer matrix structure.

\section{Full scales counts}

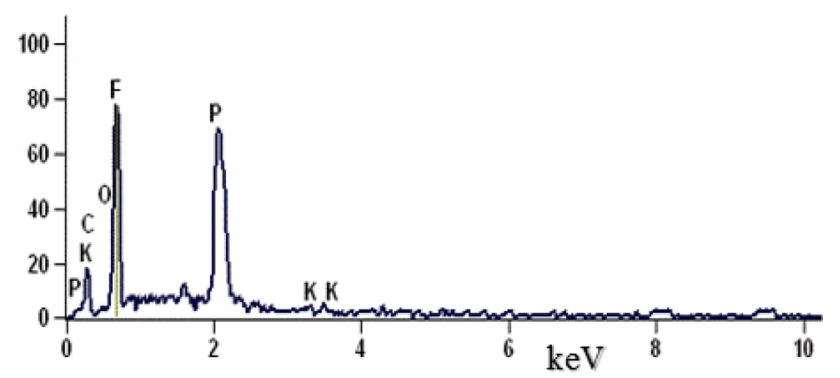

Figure 3. EDS of sample P3.

\section{$3.3 X R D$}

$\mathrm{X}$-ray diffraction (XRD) of the samples were performed on a FOCUS D8 diffractometer from Bruker with the $\mathrm{CuK} \alpha$ anode $(\lambda=1.5418 \AA)$ as the radiation source, $2 \theta$ range of $10-50^{\circ}$ using steps of $0.02^{\circ}$ at a speed of $1^{\circ} \mathrm{min}^{-1}$. Figure $4 \mathrm{a}$ shows the XRD pattern of the samples under study. In the diffractogram of sample $\mathrm{C} 1$, black coloured, $\alpha$-phase peaks are identified at $18.2^{\circ}$ relative to the plane (020) and at $20.1^{\circ}$, referring to the plane $(110)[7,12]$. The peak at $20.6^{\circ}$, referring to the planes (110) and (200), is attributed to the $\beta$-phase of PVDF $[7,12]$. Therefore, the position and width of the highest peak suggest the superposition of the $\alpha$-phase peak at $20.1^{\circ}$ and the $\beta$-phase peak at $20.6^{\circ}$. A protruding peak around $39^{\circ}$ relative to the $\beta$-phase is also noted $[13,14]$. From this, it can be inferred that the non-hydrated PVDF film prepared by this method produced a microstructure in which the $\alpha$ - and $\beta$-crystalline phases can be identified.

The spectrum in red refers to the hydrated sample C2. It suggests the presence of a large amount of amorphous matter due to the presence of water in the matrix. The water retained produces an increase in the interplanar distance. The deformation of the microstructure, as predicted by Bragg's law, implies the displacement of the diffraction peaks to smaller angles. Decreases in the Bragg angle are accompanied by the widening of the phase peaks. These phenomena add up and make it difficult to identify crystalline phase peaks. The blue spectrum is representative of the hydrated PVDF sample P0.5. One can see, how the presence of KDP disturbs the original hydrated system. In the green colour spectrum of sample P3, it can be observed that the change occurs in the sense of restoring the crystallinity of PVDF. In this spectrum, the peaks at $18.2,20.1,20.6$ and $39^{\circ}$ reappear clearly. However, such a spectrum differs from that presented in figure $4 a$, due to the appearance of peaks related to KDP.

In fact, the peaks around 24 and $32^{\circ}$ correspond to the crystallographic planes (200) and (112) in crystals of pure $\mathrm{KDP}$, as shown in figure $4 \mathrm{~b}$. With the addition of $4.0 \mathrm{wt} \%$ KDP to the blend, suppression of the crystalline peaks for
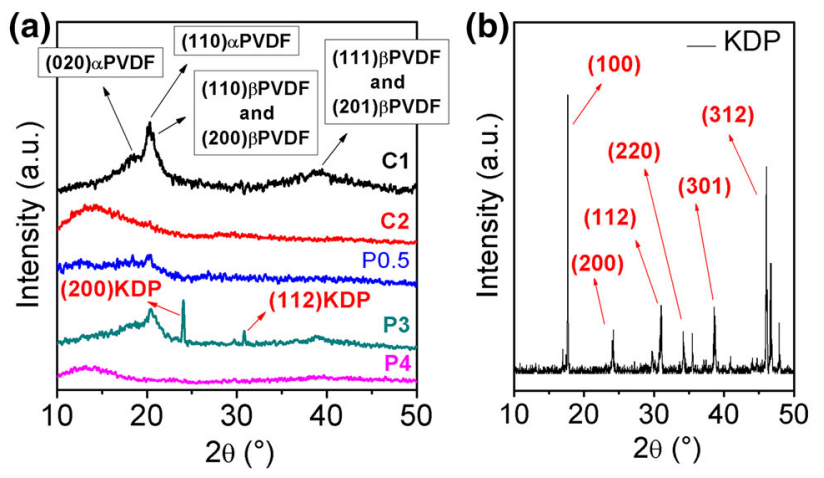

Figure 4. In (a), XRD of $\mathrm{C} 1, \mathrm{C} 2, \mathrm{P} 0.5, \mathrm{P} 3$ and $\mathrm{P} 4$ samples. In (b), the crystal diffractogram of pure KDP is shown. In sample $\mathrm{P} 3$, the KDP 'records its signature' through the peaks at 24.2 and $32^{\circ}$. 
both the polymer and the salt is again observed. In addition, the diffractogram of sample P4 (in pink) seems to indicate an optimum point for crystallinity in $3.0 \mathrm{wt} \% \mathrm{KDP}$. The spectrum of P3 very closely resembles the spectrum of $\mathrm{C} 1$, except that the latter does not present the peaks related to KDP. This is further evidence of the presence of the salt in the PVDF polymer matrix structure. Adding KDP to levels above this optimum point produces an increase in the amorphous material in PVDF. It is possible that the observed is characteristic of the method developed in this work. The suitability of the process at the cooking and drying temperature, different from that presented, should lead to the production of hybrid films of PVDF/KDP, hydrated or not, with percentages of KDP above $3 \mathrm{wt} \%$.

\subsection{FTIR spectroscopy}

A PerkinElmer UATR Two spectrophotometer was used to record FTIR transmission spectra. The instrument was calibrated to perform 10 scans per sample. Samples of PVDF/KDP composite films with different salt concentrations were subjected to Fourier transform infrared (FTIR) tests to identify possible transitions between polymorphic phases. Two strategies were adopted. In the first one, the fraction of $\beta$ phase in relation to the $\alpha$ phase was calculated through equation (1):

$$
F_{\beta}=\frac{A_{\beta}}{\left(K_{\beta} / K_{\alpha}\right) A_{\alpha}+A_{\beta}} 100 \%,
$$

where $K_{\alpha}=6.1 \times 10^{4} \mathrm{~cm}^{2} \mathrm{~mol}^{-1}$ and $K_{\beta}=7.7 \times$ $10^{4} \mathrm{~cm}^{2} \mathrm{~mol}^{-1}$ are the absorption coefficients at the wave numbers 765 and $840 \mathrm{~cm}^{-1}$, respectively. $A$ is the absorbance of each phases ( $\alpha$ and $\beta$ ) and can be calculated by expression (2):

$$
A=-\log (T)
$$

with $T$ being the transmittance at the wavenumbers $(765,840$ and $1234 \mathrm{~cm}^{-1}$ for the respective $\alpha, \beta$ and $\gamma$ phases).

As a second strategy, fractions $\mathrm{A}_{766} / \mathrm{A}_{875}, \mathrm{~A}_{840} / \mathrm{A}_{1234}$ and $\mathrm{A}_{840} / \mathrm{A}_{875}$ were calculated which provide information on percentages of $\alpha, \beta$ and $\gamma$ crystalline phases of samples consisting of crystalline and amorphous phases. In all cases, the characteristic bands of phases $\alpha$ and $\beta$ have been verified. The bands at 875 and $1180 \mathrm{~cm}^{-1}$ are present in all plotted curves and are attributed to the amorphous portion of PVDF, corresponding to the $\mathrm{CH}_{2}$ balances $[15,16]$. At each plotted curve, the amorphous phase bands are indicated with an asterisk. The vibrational modes of the PVDF crystalline phases identified in the samples are listed in table 3. Figure 4 shows the FTIR transmission curves of the samples in the wavenumber domain (between 430 and $1300 \mathrm{~cm}^{-1}$ ). In the sample $\mathrm{C} 1$, represented in figure $5 \mathrm{a}$, the characteristic bands of phases $\alpha, \beta$ and $\gamma$ are identified. These same bands are observed in figure $5 \mathrm{~b}$ relative to the hydrated sample $\mathrm{C} 2$. However, the intensity of these bands increases abruptly in the second case. The addition of water to the material sharpens the definition of three new bands. The band at $610 \mathrm{~cm}^{-1}$ refers to the $\alpha$-phase of PVDF. The other two, at 600 and $765 \mathrm{~cm}^{-1}$, correspond to its $\beta$-phase. Great attention should also be given to the appearance of the $\alpha$-phase band at $1064 \mathrm{~cm}^{-1}$. The addition of water to $\mathrm{C} 2$ intensifies all bands except the band at $1064 \mathrm{~cm}^{-1}$ which is suppressed relative to the other bands of the same spectrum. The addition of $0.5 \mathrm{wt} \% \mathrm{KDP}$ to the system causes complete suppression of the $\alpha$-phase band at $610 \mathrm{~cm}^{-1}$ as seen in figure 5c. Qualitatively, this configuration is maintained in figure $5 \mathrm{~d}$ representing the sample P3. The increase in the concentration of $4 \mathrm{wt} \% \mathrm{KDP}$ (figure 5e) induces the formation of the band at $530 \mathrm{~cm}^{-1}$.

In the FTIR of the pure KDP band was already observed, and therefore, there is a reason for this to be attributed to the flexural vibration of HO-P-OH [33] (in another situation, a band at $530 \mathrm{~cm}^{-1}$ could be interpreted due to the $\alpha$-phase of PVDF). The KDP FTIR spectrum is represented as a purple

\begin{tabular}{|c|c|c|c|}
\hline Phase & IR absorption band wave number $\left(\mathrm{cm}^{-1}\right)$ & Assignment & References \\
\hline \multirow[t]{4}{*}{$\alpha$} & 530 & $\mathrm{CF}_{2}$ bending & {$[5,12]$} \\
\hline & 610 & $\mathrm{CF}_{2}$ bending and skeletal of $\mathrm{C}(\mathrm{F})-\mathrm{C}(\mathrm{H})-\mathrm{C}(\mathrm{F})$ & {$[17-19]$} \\
\hline & 765 & $\mathrm{CF}_{2}$ bending and skeletal of $\mathrm{C}(\mathrm{F})-\mathrm{C}(\mathrm{H})-\mathrm{C}(\mathrm{F})$ & [17-19] \\
\hline & 1064 & $\mathrm{CF}_{2}$ stretching & [17-19] \\
\hline \multirow[t]{6}{*}{$\beta$} & 440 & $\mathrm{CF}_{2}$ bending & [20-22] \\
\hline & 480 & $\mathrm{CF}_{2}$ bending & [23-26] \\
\hline & 510 & Bending and wagging modes of $\mathrm{CF}_{2}$ & [26-28] \\
\hline & 600 & $\mathrm{CF}_{2}$ bending and $\mathrm{C}(\mathrm{F})-\mathrm{C}(\mathrm{H})-\mathrm{C}(\mathrm{F})$ Skeletal vibration & [5] \\
\hline & 745 & In plane bending or rocking of $\mathrm{CH}_{2}, \mathrm{CF}_{2}$ & [5] \\
\hline & 840 & $\mathrm{CH}_{2}, \mathrm{CF}_{2}$ rocking and asymmetric stretching & {$[26,28-30]$} \\
\hline \multirow[t]{2}{*}{$\gamma$} & 840 & $\mathrm{CH}_{2}, \mathrm{CF}_{2}$ rocking and asymmetric stretching & {$[31,32]$} \\
\hline & 1234 & $\mathrm{CH}_{2}$ stretching & {$[31,32]$} \\
\hline
\end{tabular}

Table 3. Vibrational modes of PVDF crystalline phases in the IR and their signatures. 

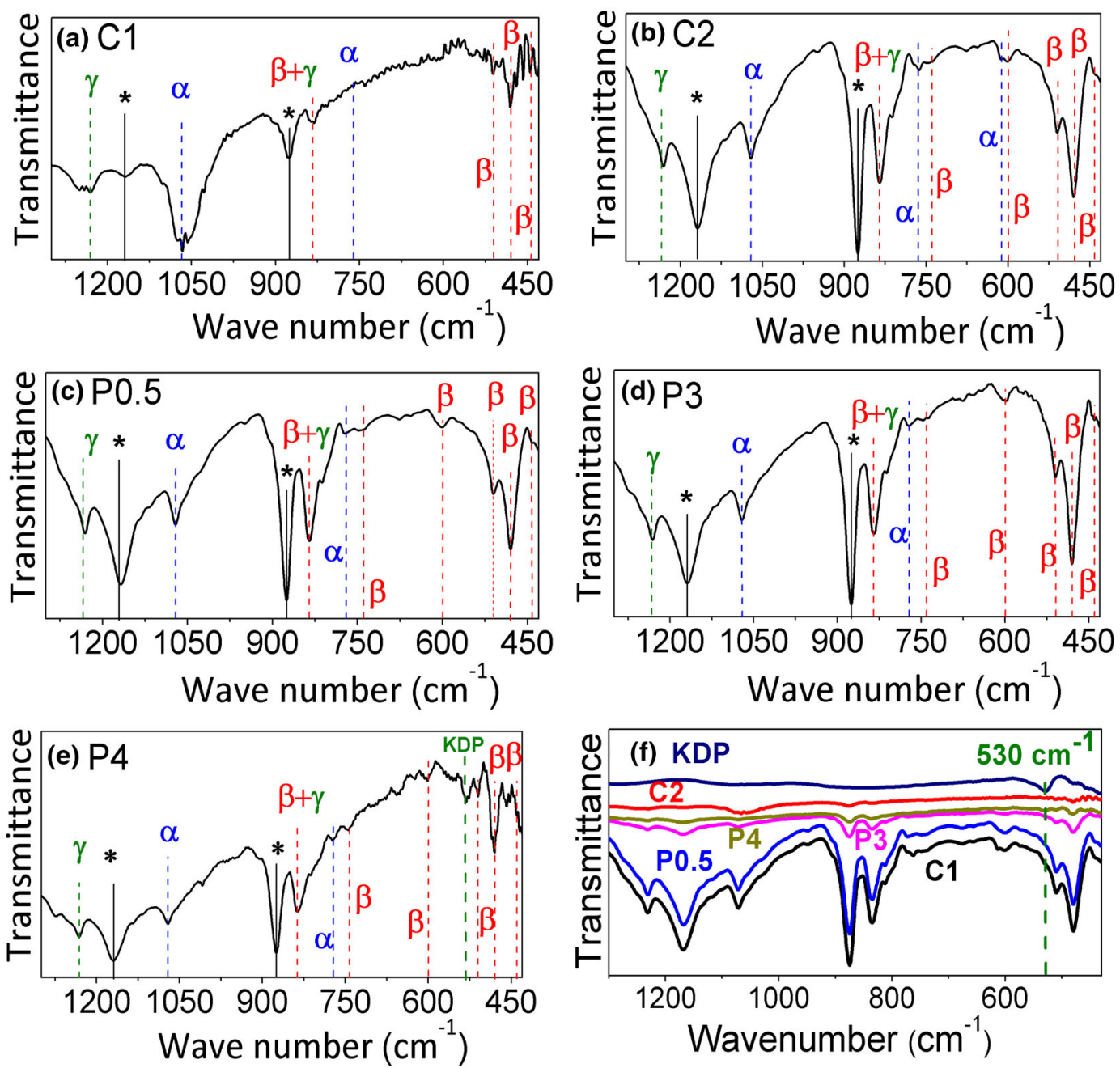

Figure 5. FTIR transmission spectrum of (a) $\mathrm{C} 1$, (b) $\mathrm{C} 2$, (c) $\mathrm{P} 0.5$, (d) $\mathrm{P} 3$ and (e) $\mathrm{P} 4$ samples. (f) On the same scale, $\mathrm{C} 1, \mathrm{P} 0.5, \mathrm{P} 3, \mathrm{P} 4$ and KDP crystals. In detail, the band is indicated at $530 \mathrm{~cm}^{-1}$, referring to KDP.

colour curve in figure $5 f$. The effect produced by water and KDP on the intensity of the IR bands in the PVDF matrix is best seen when observing the spectra of these samples on the same scale (figure 5f). As in XRD, this sequence suggests that KDP would be withdrawing water from PVDF, restoring its crystallinity. This allows the occurrence of an amorphous phase or $\alpha$-apolar crystalline phase transitions in the $\beta$-polar crystal phase. The instrument measuring the FTIR does not have sufficient sensitivity to detect the band at $530 \mathrm{~cm}^{-1}$ in samples with concentrations below $4 \mathrm{wt} \%$ KDP. Thus, the measurements by XRD and FTIR are complementary.

The relative intensity of the FTIR absorption bands may reveal relevant information about the amounts of crystalline phases of a material. The band at $875 \mathrm{~cm}^{-1}$ has been repeatedly used as the internal standard for the comparison of PVDF spectra [5]. Thus, the $A_{765} / A_{875}, A_{840} / A_{875}$ and $A_{1234} / A_{875}$ ratios, representative of the respective amounts of $\alpha, \beta$ and $\gamma$ phases in the samples studied were measured. Figure 6a shows the content of these phases as a function of the percent water content. The column sequence on the right represents sample $\mathrm{C} 1$, while on the left, sample $\mathrm{C} 2$. The fraction of the $\beta$-phase in relation to the $\alpha$-phase, $F_{\beta}$, of these samples is also shown in the same figure. Although the addition of water produces a decrease in the crystalline $\alpha, \beta$ and $\gamma$-phases, a decrease in the $A_{765} / A_{875}$ fraction is proportionally greater than $\mathrm{A}_{840} / \mathrm{A}_{875}$. Therefore, $F_{\beta}$ increases in the hydrated PVDF even with increasing the amount of the amorphous phase. Figure $6 \mathrm{~b}$ shows the evolution of the $\alpha, \beta$ and $\gamma$-phase contents as a function of the KDP content contained in the samples. In this, the $\mathrm{A}_{765} / \mathrm{A}_{875}, \mathrm{~A}_{840} / \mathrm{A}_{875}$ and $\mathrm{A}_{1234} / \mathrm{A}_{875}$ ratios indicate an upward trend in the three crystalline phases. Except for the sample $\mathrm{P} 4$, this result is very consistent with that observed in XRD. However, $F_{\beta}$ undergoes distinct variations. In relation to hydrated PVDF and devoid of KDP, $F_{\beta}$ is successively higher in samples containing 0.5 and $3 \mathrm{wt} \% \mathrm{KDP}$. 


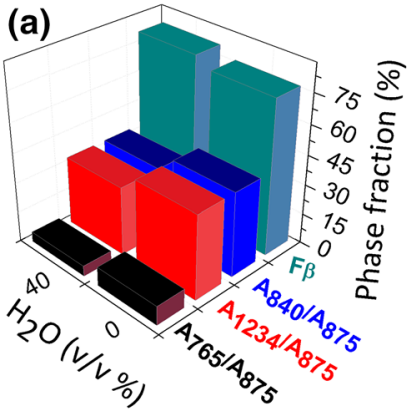

(b)

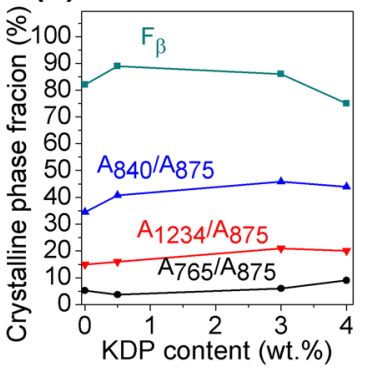

Figure 6. Crystalline phase fractions of PVDF/KDP composites: (a) as a function of water content; and in (b) as a function of KDP content.

\subsection{Dielectric characterization}

The dielectric characteristics of the material are important to know the transport phenomena and the network dynamics in the crystal. It also provides information about the nature of the atoms, ions, bonds and the polarization mechanism in the material [34]. Measurements of electrical impedance of the capacitors were performed with the aid of an analyser LCR meter 4284A (Agilent). The measurements were performed at room temperature $\left(\sim 23^{\circ} \mathrm{C}\right)$ in the frequency range of $1.0 \mathrm{kHz}-1.0 \mathrm{MHz}$, using $500 \mathrm{mV}$ as the electric potential amplitude. Information about the capacitance and loss factor of each material was extracted. The dielectric constants $\varepsilon_{\mathrm{r}}$ were obtained through equation (3):

$$
C=\varepsilon_{\mathrm{r}} \cdot \varepsilon_{\mathrm{o}} \cdot A / L,
$$

where $C$ is the capacitance of the capacitor supplied by the impedance analyser, $\varepsilon_{0}$ the vacuum electrical permittivity, $A$ the surface area of each sample and $L$ its thickness.
Figure 7a shows the plot of the dielectric constant vs. frequency for samples C1, C2, P0.5, P3 and P4. The values of the dielectric constants of all the evaluated materials decrease with frequency as is common in dielectrics. At a low frequency, the PVDF dipoles align alternately with the applied electric field. At high frequencies, the dipoles do not have enough time to align, before the field changes direction [12]. The high value of the low-frequency dielectric constant may be due to the presence of all polarizations (space charge, orientation, electronic and ionic) and its low value at high frequencies may be due to an significant loss in all polarizations gradually [35]. Figure $7 \mathrm{~b}$ shows the evolution of the dielectric constant of the hydrated materials at a frequency of $1.0 \mathrm{kHz}$, relative to the KDP content. There is no loss of this characteristic in the polymer due to an increase in KDP. As expected, the highest value of the dielectric constant is obtained for the sample P0.5, since this one presented a higher value of $F_{\beta}$. Even in the samples $\mathrm{P} 0.5$ and $\mathrm{P} 3$, which presented an expressive increase of crystallinity and $F_{\beta}$, the increase in the dielectric constant in the composites is relatively small. This suggests values close to the dielectric constants of the polymer and the salt at the same frequency and at the same temperature. The KDP dielectric constant was measured by Prince et al [34] over a wide temperature and frequency range. The value of the dielectric constant of pure KDP crystals found by them at a frequency of $1.0 \mathrm{kHz}$ and at a temperature of $40^{\circ} \mathrm{C}$, for example, is close to 8 . Figure 7a shows the experimental value of 8.8 for the dielectric constant of pure PVDF under the same conditions.

It is known that the presence of salt introduces irregularities on the surface of the materials as observed in the SEM study. This makes capacitance measurements very difficult. Nevertheless, for all samples, the dielectric loss factor remained relatively low as shown in figure $7 \mathrm{c}$. All materials had dielectric losses below 0.12 at the frequency of $1.0 \mathrm{kHz}$. The dielectric loss curves show that this property is also strongly dependent on the applied electric field frequency.
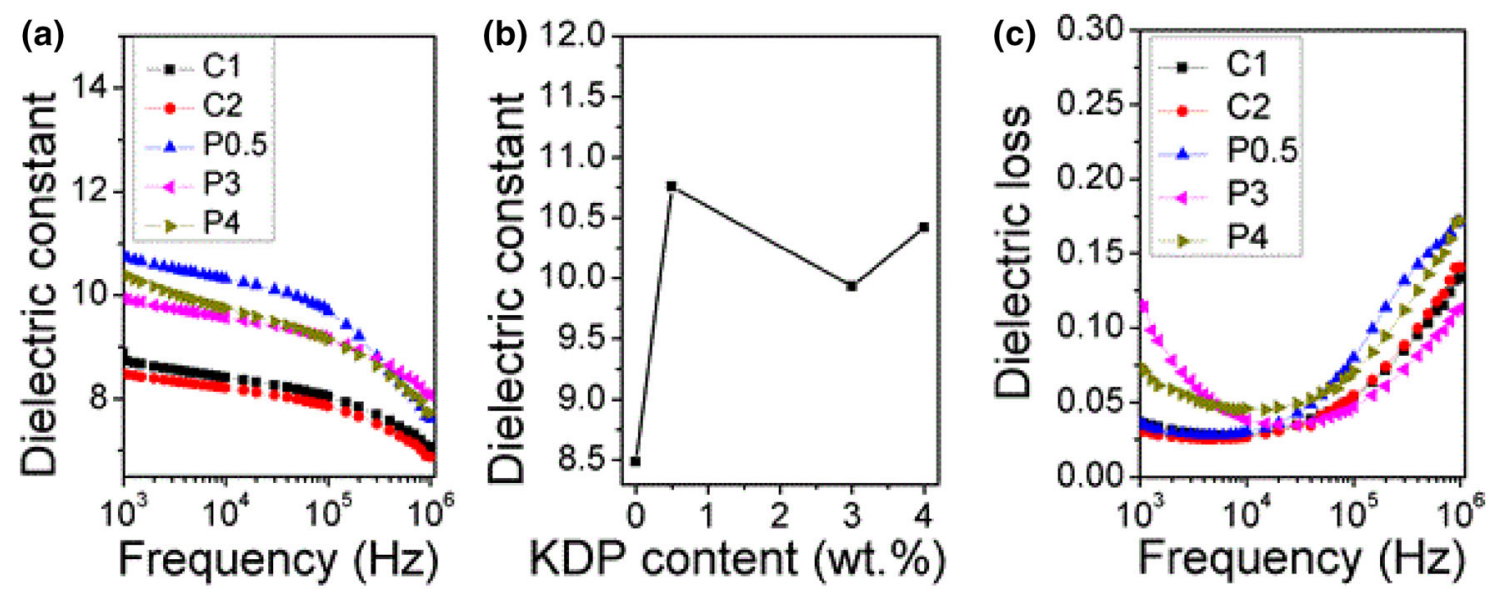

Figure 7. (a) Dielectric constant vs. frequency of $\mathrm{C} 1, \mathrm{C} 2, \mathrm{P} 0.5, \mathrm{P} 3$ and $\mathrm{P} 4$ samples. (b) Dielectric constant of $\mathrm{PVDF} / \mathrm{KDP}$ hydrated nanocomposites $v s$. KDP content at a frequency of $1.0 \mathrm{kHz}$ at room temperature. (c) Dielectric loss factor of the PVDF/KDP nanocomposite as a function of frequency. 


\section{Conclusion}

The present work for the first time described a process for the preparation of hybrid films composed of PVDF and KDP, using the DMF and water mixture as solvents. The nonpolarized materials by an external field were characterized by different techniques. The membranes were interesting as a hydrophilicity, porosity and crystallinity control of PVDF films, suggesting potentials for application in filtration membranes, pressure sensors and actuators among other devices. Compared to the others, the composite film of PVDF/KDP with content of $0.5 \mathrm{wt} \% \mathrm{KDP}$, presented a higher increase in the $\beta$-phase. The composite PVDF/KDP films had higher electrical permittivity than the standard PVDF, including the $4 \mathrm{wt} \%$ of KDP film, in which case, it was found smaller $\beta$-polar phase fraction. The improvement of the capacitive properties of the films observed makes them promising candidates for the replacement of conventional PVDF in electromechanical devices.

\section{Acknowledgements}

We would like to thank the National Council for Scientific and Technological Development/CNPQ and the Foundation of Support and Research of the Federal District/FAP-DF for financial support.

\section{References}

[1] Prateek, Thakur V K and Gupta R K 2016 Chem. Rev. 1164260

[2] Li Y, Krentz T M, Wang L, Benicewics B C and Schadler L S 2014 ACS Appl. Mater. Interfaces 66005

[3] Kang G and Cao Y 2014 J. Membr. Sci. 463145

[4] Liu F, Hashim N A, Liu Y, Abed M and Li K 2011 J. Membr. Sci. 3751

[5] Greeshma T, Balaji R and Jayakumar S 2013 Ferroelectr. Lett. 4041

[6] Song R, Xia G, He L, Zhao Q and Ma Z 2013 J. Colloid Interface Sci. 40150

[7] Wang Y, Zhou X, Chen Q, Chu B and Zhang Q 2010 IEE Trans. Dielectr. Electr. Insul. 171036

[8] Kumar J and Awasthi A M 2013 Appl. Phys. Lett. 103132903

[9] Melo F E A, Moreira S G C, Chaves A S, Guedes I, Freire P T C and Mendes-Filho J 1999 Phys. Rev. B 53276
[10] Sencadas V, Gregorio R and Lanceros-Mendez S 2006 J. NonCryst. Solids $\mathbf{3 5 2} 2226$

[11] Yang L, Ji H, Qiu J, Zhu K and Shao B 2014 J. Intell. Mater. Syst. Struct. 25858

[12] Jana S, Garain S, Sen S and Mandal D 2015 Phys. Chem. Chem. Phys. 1717429

[13] Meng Q, Li W, Zheng Y and Zhang Z 2010 J. Appl. Polym. Sci. 1162674

[14] Tao M, Liu F, Ma B and Xue L 2013 Desalination 316137

[15] Yang L, Qiu J, Ji H, Zhu K and Wang J 2014 Compos. A 65 125

[16] Jiang X, Zhao X, Peng G, Liu W, Liu K and Zhan Z 2017 Curr. Appl. Phys. 1715

[17] Sharma M, Madras G and Bose S 2014 Phys. Chem. Chem. Phys. 1614792

[18] Gaur M S, Indolia A P, Rogachev A A and Rahachou A V 2015 J. Therm. Anal. Calorim. 1221403

[19] Sharma M, Madras G and Bose S 2014 Phys. Chem. Chem. Phys. 162693

[20] El Achaby M, Arrakhiz F E, Vaudreuil S, Essassi E M, Qaiss A and Bousmina M 2013 Polym. Eng. Sci. 5334

[21] El Achaby M, Arrakhiz F, Vaudreuil S, Essassi E and Qaiss A 2012 Appl. Surf. Sci. 2587668

[22] Patro T U, Mhalgi M V, Khakhar D and Misra A 2008 Polymer 493486

[23] Tashiro K and Kobayashi M 1989 Phase Transit. 18213

[24] Buonomenna M, Macchi P, Davoli M and Drioli E 2007 Eur. Polym. J. 431557

[25] Wang W, Zhang S, Srisombat L O, Lee T R and Advincula R C 2011 Macromol. Mater. Eng. 296178

[26] Gomes J, Nunes J S, Sencadas V and Lanceros-Mendez S 2010 Smart M. Struct. 19065010

[27] Kobayashi M, Tashiro K and Tadokoro H 1975 Macromolecules $\mathbf{8} 158$

[28] Salimi A and Yousefi A 2003 Polym. Test. 22699

[29] Lopes A C, Tavares C J, Neves I C and Lanceros-Mendez S J 2011 Phys. Chem. 11518076

[30] Bormashenko Y, Pogreb R, Stanevsky O and Bormashenko E 2004 Polym. Test. 23791

[31] Gregorio R and Capitao R 2000 J. Mater. Sci. 35299

[32] Jia N, Xing Q, Liu X, Sun J, Xia G, Huang W et al 2015 J. Colloid Interface Sci. 453169

[33] Rajesh P, Silambarasan A and Ramasamy P 2014 Mater. Res. Bull. 49640

[34] Prince M U, Therese P S and Perumal S 2015 Int. J. Eng. Res. Appl. 57

[35] Smyth CP 1965 Dielectric behaviour and structure (New York: McGraw-Hill) p 132 